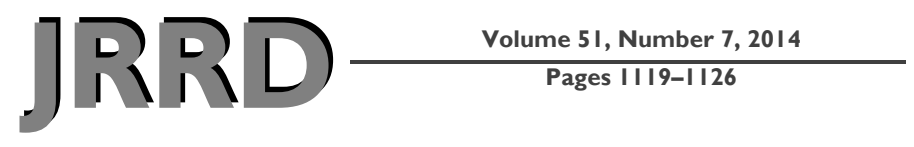

\title{
Reduction of residual limb volume in people with transtibial amputation
}

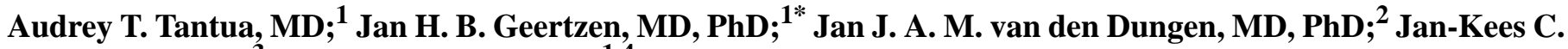 \\ Breek, MD, PhD; ${ }^{3}$ Pieter U. Dijkstra, PhD ${ }^{1,4}$ \\ ${ }^{1}$ Department of Rehabilitation Medicine, University Medical Center Groningen, Center for Rehabilitation, Groningen, \\ the Netherlands; ${ }^{2}$ Department of Vascular Surgery, University Medical Center Groningen, University of Groningen, \\ Groningen, the Netherlands; ${ }^{3}$ Department of Surgery, Martini Hospital Groningen, Groningen, the Netherlands; \\ ${ }^{4}$ Department of Oral and Maxillofacial Surgery, University Medical Center Groningen, University of Groningen, \\ Groningen, the Netherlands
}

\begin{abstract}
The early postoperative phase after transtibial amputation is characterized by rapid residual limb volume reduction. Accurate measurement of residual limb volume is important for the timing of fitting a prosthesis. The aim of this study was to analyze the reduction of residual limb volume in people with transtibial amputation and to correlate residual limb volume with residual limb circumference. In a longitudinal cohort study of 21 people who had a transtibial amputation, residual limb volume was measured using a laser scanner and circumference was measured using a tape measure $1 \mathrm{wk}$ postamputation and every 3 wk thereafter until 24 wk postamputation. A linear mixed model analysis was performed with weeks postamputation transformed according to the natural logarithm as predictor. Residual limb volume decreased significantly over time, with a large variation between patients. Residual limb volume did not correlate well with circumference. On average, residual limb volume decreased $200.5 \mathrm{~mL}$ (9.7\% of the initial volume) per natural logarithm of the weeks postamputation. The decrease in residual limb volume following a transtibial amputation was substantial in the early postamputation phase, followed by a leveling off. It was not possible to determine the specific moment at which the residual limb volume stabilized.
\end{abstract}

Key words: amputation, fluctuation, laser scanner, longitudinal study, lower limb, measurements, rehabilitation, residual limb, residual limb volume, transtibial.

\section{INTRODUCTION}

To fit a prosthesis after a transtibial amputation (TTA) is of utmost importance in the rehabilitation process. People with TTA with an adequately fit prosthesis are more likely to rehabilitate quicker and function better in all aspects of daily life than those with fitting problems [1]. There are also psychological advantages of a goodfitting prosthesis, such as acceptance of the amputation and restoration of body image [2].

The characteristics of the residual limb are important for the success of prosthetic fitting. Before fitting of a definitive prosthesis, edema must have resolved, the wound should have healed, the residual limb shape should be conical, and the residual limb volume should be stable as the residual limb reaches maturation $[1,3-5]$.

\footnotetext{
Abbreviations: $\mathrm{CAD}=$ computer-aided design, $\mathrm{CAM}=$ computer-aided manufacturing, $\mathrm{SE}=$ standard error, TTA = transtibial amputation.

*Address all correspondence to Jan H. B. Geertzen, MD, PhD; Department of Rehabilitation Medicine, University Medical Center Groningen, Center for Rehabilitation, PO Box 30.001 (HPC CB 41), 9700 RB Groningen, the Netherlands; +31-(0)50-3612295; fax: +31-(0)50-3619251.

Email: j.h.b.geertzen@umcg.nl

http://dx.doi.org/10.1682/JRRD.2013.11.0243
} 
Edema, supported by a shrinking program, will largely subside during the first two postoperative months, while muscle atrophy may continue for many months [6-7].

Accurate measurement of the residual limb volume is important to determine the right moment for definitive prosthetic fitting [8-9]. Several methods for the measurement of residual limb volume exist: circumferential residual limb measurement [7], water immersion measurement [10], cast filling, contact scanning methods [11], laser scanning methods [8,12-13], ultrasound measurement [14], bioimpedence [15], (spiral) computed tomography scans [1617], and magnetic resonance imaging scans [18].

Ideally, a reliable, cheap, and easy to use method for measuring residual limb volume should be available for clinical practice. In everyday practice, residual limb circumference measured with a tape is often used to assess volume stabilization. The CAPOD (Biomechanics Laboratory; Jönköping, Sweden), a computer-aided design (CAD)/computer-aided manufacturing (CAM) system, was claimed to be accurate and reliable [11,13]. Established residual limb volume stabilization $120 \mathrm{~d}$ postamputation with the CAPOD system in one study [19] has not been verified yet. Unfortunately, this system is not available anymore.

Recently, four different clinical methods to measure residual limb volume have been analyzed [8,12]. The Omega Tracer system (Ohio Willow Wood; Mt. Sterling, Ohio) appeared most accurate and reliable in people with TTA.

The aim of this study was to analyze the reduction of residual limb volume in people with TTA using the Omega Tracer system and to correlate residual limb volume with residual limb circumference.

\section{METHODS}

\section{Subjects}

From October 2010 until November 2012, patients who recently had a TTA were asked to participate in this study.

The indications for a TTA were peripheral vascular disease, with or without diabetes mellitus, trauma, malignancy, or other reasons. Patients were admitted to the general, vascular, or the orthopedic surgery ward of the University Medical Center Groningen or the Martini Hospital in Groningen, the Netherlands.
Within 1 wk after TTA, participants were included when they were motivated and physically fit enough to rehabilitate with a prosthesis. Written informed consent was obtained after an explanation of the procedure. Participants were excluded when their physical condition did not allow them to undergo the measurements, when they were mentally incapacitated, or when they had no intention of using a prosthesis.

This study was approved by the Medical Ethical Board of the University Medical Hospital Groningen (NL30086.042.10) and by the Medical Ethical Board of the Martini Hospital Groningen.

\section{Materials and Methods}

Before measurements, participants removed their liner or wound dressing. On every occasion, a new thin, nylon stocking was placed over the residual limb. Elevated markers were placed medially and laterally of the knee joint and at the distal part of the tibia. Reflective dots were placed at random distally to the knee joint. With the Omega Scanner, a handheld CAD scanner originally designed to create orthoses and prostheses for the human body, multiple digital photographs were made. With the participant sitting with the residual limb horizontally, the residual limb was scanned from all sides in random order from knee joint to the distal end of the limb. With the Omega Tracer system software program, scanning data were used to create a three-dimensional model of the residual limb. The elevated markers were used to recognize the knee joint and the distal part of the tibia on the three-dimensional view. The volume of the residual limb from the distal end of the residual limb to the knee joint was then calculated $[8,12]$.

At the same time, residual limb circumference was measured with a standard tape measure at the most distal part of the tibia because clinically this method is often used to evaluate the residual limb. The repeatability coefficient of the Omega Tracer for determining residual limb volume in people with TTA was found to be $129 \mathrm{~mL}$ [12]. For a spring tape measurement of calf circumference in nondisabled people, this value was $5.1 \mathrm{~mm}$ [20]. For tape measurement for the assessment of leg edema, the reproducibility index was 3.3 percent [21].

The first measurements were done on the surgical ward in the first postoperative week. Volume measurements were performed twice per session and recorded for further analysis. Subsequently, measurements were done every $3 \mathrm{wk}$ (i.e., week 3, 6, 9, 12, 15, 18, 21, 24 postamputation), either 
in the rehabilitation center, at the patient's home, or at the skilled nursing facility where the patient was staying.

The measurements were done by two researchers who were trained in conducting the measurements.

\section{Study Variables}

Patient characteristics, including sex, age, reason for amputation, and presence of comorbidities were documented.

\section{Statistical Analysis}

A linear mixed model analysis was performed. The influence of time (weeks postamputation), reason for amputation, use of prosthesis, and sex were explored in the analysis (-2 log-likelihood criterion). Two models were analyzed, one using the actual residual limb volume and one using percentage of the residual limb volume of the first measurement as outcome variable. In the first model, intercept was modeled as fixed and as random. In the second model, the intercept was modeled as fixed. The level of statistical significance for all tests was set to $p<0.05$. Random effects were explored in both models. Time was transformed to a natural logarithm (ln weeks postamputation). Residuals were explored for a normal distribution.

The correlation between residual limb volume and residual limb circumference was calculated with Spearman rho. SPSS Statistics 20 statistical software (IBM Corporation; Armonk, New York) was used for all analyses.

\section{RESULTS}

Between October 1, 2010, and November 1, 2012, 22 people with amputation were included in the study.

The measurements of one participant showed an increase in residual limb volume, caused by inaccurate measurement while the wound bandage was left in place. Data of this participant were excluded from analysis. Patient characteristics have been summarized in the Table.

Three participants died during the research period, but available measurements of these participants were included in the analysis. Immediate postoperative wound dressing varied between participants from plaster cast to a semirigid dressing or wound or elastic bandage (Table). Thereafter, different residual limb treatments were provided, including compression liner and silicon liner. The timing of the different dressings depended on the clinical situation of the participant and preferences within the hospital or departments
Table.

Patient characteristics. $N=21$.

\begin{tabular}{|c|c|}
\hline Characteristic & $\begin{array}{c}\text { Mean } \pm \text { SD or } \\
\text { Number (\%) }\end{array}$ \\
\hline Age (yr) & $57.0 \pm 16.6$ \\
\hline Sex (male) & $17(81)$ \\
\hline \multicolumn{2}{|l|}{ Reason for Amputation } \\
\hline Peripheral Vascular Disease & $9(43)$ \\
\hline Infection & $5(24)$ \\
\hline Other & $3(14)$ \\
\hline Diabetes & $2(10)$ \\
\hline Trauma & $2(10)$ \\
\hline \multicolumn{2}{|l|}{ Comorbidity } \\
\hline Peripheral Vascular Disease & $3(14)$ \\
\hline Diabetes & $11(52)$ \\
\hline Renal Disease & $5(24)$ \\
\hline Previous TTA on Other Leg & $3(14)$ \\
\hline Side of Amputation (left) & $11(52)$ \\
\hline \multicolumn{2}{|l|}{ Immediate Postoperative Dressing ${ }^{*}$} \\
\hline None & 4 (19) \\
\hline Plaster Cast & 4 (19) \\
\hline Semirigid Dressing & $9(43)$ \\
\hline Wound Bandage & $3(14)$ \\
\hline Elastic Bandage & $1(5)$ \\
\hline \multicolumn{2}{|l|}{ Hospital of Admittance } \\
\hline University Medical Center Groningen & $14(67)$ \\
\hline Martini Hospital & $7(33)$ \\
\hline \multicolumn{2}{|l|}{ Lost to Follow Up Cause } \\
\hline Death & $3(14)$ \\
\hline Noncompliance & $1(5)$ \\
\hline Comorbidity & $1(5)$ \\
\hline \multicolumn{2}{|c|}{$\begin{array}{l}\text { Note: Because percentages were rounded to an integer, su } \\
\text { "reason for amputation" did not add up to } 100 \% \text {. } \\
\text { *Postoperative dressing } 1 \text { wk postamputation. } \\
\text { SD = standard deviation, TTA = transtibial amputation. }\end{array}$} \\
\hline
\end{tabular}

within the hospital. The median interval (interquartile range) between amputation and a definitive prosthesis was $63.5 \mathrm{~d}$ (50.5-101.3 d).

Substantial differences in residual limb volume between participants were found. Residual limb volume reduced over time in a nonlinear way (Figure 1(a)). After transforming time to ln time, the decrease of residual limb volume approximated linearity.

In the linear mixed model (first order autoregressive covariance structure), the mean residual limb volume at 
week 1 after amputation was 2,081.0 mL (standard error $[\mathrm{SE}]=95.7 \mathrm{~mL}$ ), and it reduced by $200.5 \mathrm{~mL}$ per $\mathrm{ln}$ weeks. In other words-

\section{Estimated decrease in residual limb volume $=$ 2,081.0 $\mathrm{mL}-200.5 \mathrm{~mL} \times$ ln weeks. (1)}

On average, the residual limb volume decreased 9.7 percent of the initial residual limb volume per ln weeks.
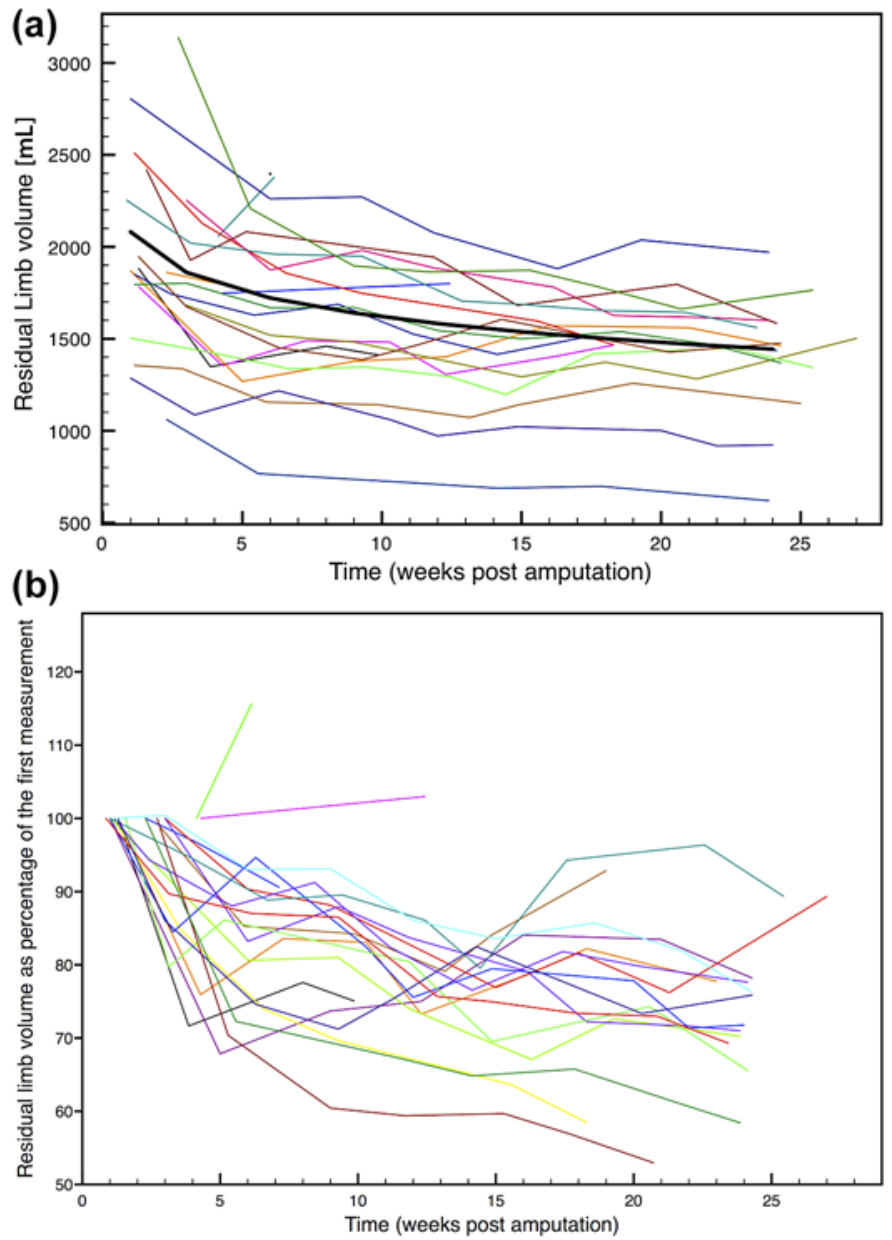

Figure 1.

(a) Changes in residual limb volume over time. Each thin colored line represents one person with amputation. Point represents one measurement of one person with amputation. Bold black line represents estimated decrease in residual limb volume $=2,081.0 \mathrm{~mL}-200.5 \mathrm{~mL} \times$ In weeks. (b) Residual limb volume as percentage of first measurement in time. Each thin colored line represents one person with amputation (colors do not match colors from (a)).
No significant effect was found for reason for amputation $(p=0.38)$, use of prosthesis $(p=0.09)$, sex $(p=$ $0.46)$, or age $(p=0.46)$.

Figure 1(b) illustrates the change in residual limb volume when normalizing the initial residual limb volume at 100 percent.

Two participants showed an increase in residual limb volume in the early postamputation phase. In one participant, volume increased because of a fast overall weight gain as a result of cardiac fluid retention. For the other, no reason could be identified. This participant was lost to follow-up because of noncompliance to appointments.

Over a period of $24 \mathrm{wk}$, residual limb volume did not stabilize, but seemed to level off. In the last $3 \mathrm{wk}$, the average decrease was $28.1 \mathrm{~mL}$.

In a mixed model, the average residual limb circumference in the first postoperative week was $38.2 \mathrm{~cm}$ ( $\mathrm{SE}=$ $0.9 \mathrm{~cm}$ ) and reduced with $2.6 \mathrm{~cm}$ per ln weeks. Correlation calculated with Spearman rho between residual limb volume and circumference differed per measurement, ranging from 0.35 to 0.95 (Figure 2). The explained variance (Spearman rho ${ }^{2}$ ) ranged from 12 to 90 percent.

\section{DISCUSSION}

In $24 \mathrm{wk}$, the residual limb volume in people with TTA decreased with a great variability between participants. The decrease was substantial in the early postamputation phase but appeared to level off afterward. Apart from time, there were no other significant relationships between the studied

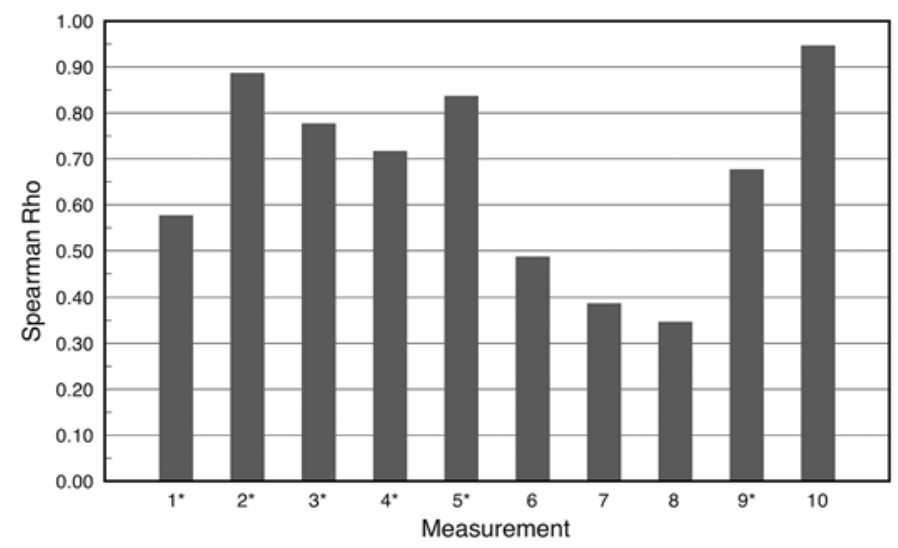

Figure 2.

Correlation between residual limb volume and circumference at different measurement times. ${ }^{*}$ Significance $p<0.05$. 
variables and residual limb volume. This lack of significant findings could be due to the relatively small group of participants. In the immediate postoperative phase, wound dressing varied between participants from plaster cast to a semirigid dressing and wound or elastic bandages; thereafter, liners were provided. However, the moment these liners were applied differed per participant and was based on the clinical situation.

The residual limb circumference also decreased significantly over time. But there was no consistent correlation with residual limb volume over time. The residual limb appears to fluctuate with regard to composition and changes its shape continuously because of redistribution of soft tissue [22] as a result of activities, edema, venous pooling, muscle contraction, and atrophy. This fluctuation may not be reflected similarly in volume and circumference measurements. Additionally, difference in measurement errors may have reduced the consistency of the correlation between residual limb volume and circumference over time.

The changes in shape and volume of the residual limb affect the quality of socket fit. The results of the current study underline the importance of close observation of every individual with TTA since residual limb change differs between people with TTA and may change over the long-term. In general, it is not possible to define the best moment for prosthetic fitting. Since early rehabilitation is important, stabilization of volume changes should not be awaited. Therefore, it is important to identify the moment when volume changes have leveled off sufficiently in each individual, permitting prosthetic fitting.

This study shows that the point of maturation (stable residual limb volume) cannot be defined as a specific point in time. Maturation not only differs per individual, but also appears to stretch over time. In a recent review, a residual limb was regarded as mature $18 \mathrm{mo}$ after amputation, although the residual limb volume continued to fluctuate [23]. The trend in decrease of change in residual limb volume can perhaps be helpful in determining the best moment for fitting a definitive prosthesis.

In everyday practice, a rehabilitation team, including physiatrist, physiotherapist, and certified prosthetist, decide, based on experience, wound healing, residual limb shape, and circumference, when a residual limb is mature enough to fit a prosthesis.

This study shows a decrease in residual limb volume, which on average is consistent with the negative power function that characterized volume changes in earlier research by Lilja and Oberg [19]. In 11 people with amputation, a residual limb volume decrease of 17 to 35 percent was found after $160 \mathrm{~d}$, and stabilization was found after $120 \mathrm{~d}$. However, in our study fluctuation in residual limb volume was still apparent after $160 \mathrm{~d}$ and varied considerably between participants. Possible explanations for this difference may be that in the Lilja and Oberg study only people with amputation with peripheral vascular disease were included [19]. Moreover, measurements were done with the CAPOD system, a CAD/CAM system that may have conferred other results than the Omega Tracer system.

In an earlier study in which water displacement measurement was used to measure residual limb volume in 49 people with amputation, a vast variation in residual limb volume was found between individuals, as observed in our study [24]. It was concluded that periods of static volume or even small increases may be an indication that residual limb volume fluctuates around a decreasing average volume, possibly with periods of gross volume loss interspersed with plateaus in volume change. These findings seem in agreement with the results of our study.

In another study, the maturation rates of 36 healed TTA residual limbs were analyzed by measurement of the residual limb volumes by water displacement and measurement of circumference using a tape measure [7]. Consistent with our results, the limb circumference did not correlate well with volume. However, in 23 people with amputation, circumference changed in the same direction over time, demonstrating statistically significant relations $(p<0.05)$ dependent on the shrinking method used. In more than half of the people, it was impossible to determine volume stabilization.

In a recent study analyzing four different clinical methods of measuring residual limb volume in people with TTA, the repeatability coefficient of the water displacement method (143 $\mathrm{mL}$ ) was higher than that of the Omega Tracer system $(129 \mathrm{~mL})$, indicating that the Omega Tracer system is more reliable in measuring residual limb volume [12]. Because the water displacement method was used in the aforementioned studies, it is therefore questionable whether the results are really in agreement with ours or not.

In contrast with earlier studies, our study did not include only people with peripheral vascular disease, but also people with other indications for amputation and with other comorbidities. Nevertheless, the sample size was relatively small and it was not possible to distinguish 
differences in postoperative volume reduction method or among subgroups of people with amputation. Additionally, effects of prosthesis use could not be established, although the $p$-value was 0.09 , suggesting that in a larger sample size effects of prosthesis use might be established.

Another flaw is that, because of logistical and practical reasons, it was not always possible to do measurements at specific moments of the day or before or after a certain activity (for example, physiotherapy). This lack of consistency may have influenced volume measurements because short-term fluctuations in residual limb volume depend on the moment of measurement after doffing the prosthesis [6]. In a recent study $(n=30)$, activity before doffing intensified the postdoffing limb fluid volume increase from 1.1 to 8.3 percent [25]. This was, among other things, dependent on the activity before doffing the prosthesis (sit, walk) or whether the participant had also doffed the liner shortly before or not. Limb fluid volume increased quickly during the first minute after doffing and then less quickly afterward. Sanders et al. also recommended taking into account the activity of the person with amputation before measurement [25]. A stable limb shape may be important when using imaging systems that take more than a few seconds to image the limb, like for example laser scanners.

During the collection of data, several technical, hardware, and software problems were encountered. For example, during scanning in a sunny environment, ultravioletradiation interfered with the camera detecting the reflected laser beams. Scanning was also in some measurements hindered because of a roll of nonreflective dots. These problems sometimes resulted in stopping or postponing the measurements (in 12/192 measurements, 6.3\%). It was therefore not always possible to measure at the same time after doffing the prosthesis. In addition, scanning in the presence of wounds or sutures was difficult because they interfered with applying the nylon stocking.

Three participants (14\%) died during the research period, which is remarkably less than was found recently. The mortality rate of people with TTA with vascular disease, with or without diabetes or with infection, in the northern Netherlands was 44 percent in 2003 to 2004 [26]. In accordance with an earlier study, fewer people with amputation who went to a rehabilitation center died in the first year after amputation than people with amputation who went to a skilled nursing facility after their initial hospital stay [1]. It is likely that people with ampu- tation who participated in this study were in better physical condition.

\section{CONCLUSIONS}

Residual limb volume in people with TTA decreases in the postoperative phase. However, there is a large inter- and intraindividual variability.

Future research in a larger group of people with amputation is necessary to determine the time frame of residual limb volume stabilization and the influence of factors like residual limb treatment or comorbidity on residual limb volume.

\section{ACKNOWLEDGMENTS}

\section{Author Contributions}

Study concept and design: A. T. Tantua, J. H. B. Geertzen, P. U. Dijkstra, J. J. A. M. van den Dungen, J. C. Breek.

Acquisition of data: A. T. Tantua.

Analysis and interpretation of data: A. T. Tantua, J. H. B. Geertzen, P. U. Dijkstra.

Drafting of manuscript: A. T. Tantua.

Critical revision of manuscript for important intellectual content:

A. T. Tantua, J. H. B. Geertzen, J. C. Breek, P. U. Dijkstra,

J. J. A. M. van den Dungen.

Obtained funding: A. T. Tantua.

Study supervision: J. H. B. Geertzen.

Final approval of manuscript: A. T. Tantua, J. H. B. Geertzen, J. J. A. M. van den Dungen, J. C. Breek, P. U. Dijkstra.

Financial Disclosures: No commercial party having a direct financial interest in the results of the research supporting this article has or will confer a benefit on the authors or any organization with which the authors are associated.

Funding/Support: This material was based on work supported by a grant received from the Foundation OIM (Assen, the Netherlands), which financed traveling expenses for the participants and the researcher. Also, materials such as nylon stockings and reflective dots were financed. OIM Orthopedie (Assen, the Netherlands) provided one of the two Omega Tracer system systems for the duration of the study. OrthoEurope (Houten, the Netherlands) delivered the Omega Tracer system and provided technical support during the study. There are no financial relationships between the authors and the abovementioned companies.

Institutional Review: The academic hospital research ethics board approved this study's methodology prior to the start of participant recruitment and testing (NL30086.042.10).

Participant Follow-Up: The authors do not plan to inform the participants of the publication of this study unless the participants have requested to be informed. 


\section{REFERENCES}

1. Schoppen T, Boonstra A, Groothoff JW, de Vries J, Göeken LN, Eisma WH. Physical, mental, and social predictors of functional outcome in unilateral lower-limb amputees. Arch Phys Med Rehabil. 2003;84(6):803-11. [PMID:12808530] http://dx.doi.org/10.1016/S0003-9993(02)04952-3

2. Murray CD, Fox J. Body image and prosthesis satisfaction in the lower limb amputee. Disabil Rehabil. 2002;24(17): 925-31. [PMID:12519488] http://dx.doi.org/10.1080/09638280210150014

3. van Velzen AD, Nederhand MJ, Emmelot CH, Ijzerman MJ. Early treatment of trans-tibial amputees: Retrospective analysis of early fitting and elastic bandaging. Prosthet Orthot Int. 2005;29(1):3-12. [PMID:16180373] http://dx.doi.org/10.1080/17461550500069588

4. Aulivola B, Hile CN, Hamdan AD, Sheahan MG, Veraldi JR, Skillman JJ, Campbell DR, Scovell SD, LoGerfo FW, Pomposelli FB Jr. Major lower extremity amputation: Outcome of a modern series. Arch Surg. 2004;139(4):395-99, discussion 399. [PMID:15078707]

http://dx.doi.org/10.1001/archsurg.139.4.395

5. Wong CK, Edelstein JE. Unna and elastic postoperative dressings: Comparison of their effects on function of adults with amputation and vascular disease. Arch Phys Med Rehabil. 2000;81(9):1191-98. [PMID:10987161] http://dx.doi.org/10.1053/apmr.2000.3780

6. Zachariah SG, Saxena R, Fergason JR, Sanders JE. Shape and volume change in the transtibial residuum over the short term: Preliminary investigation of six subjects. J Rehabil Res Dev. 2004;41(5):683-94. [PMID:15558398] http://dx.doi.org/10.1682/JRRD.2003.10.0153

7. Golbranson FL, Wirta RW, Kuncir EJ, Lieber RL, Oishi C. Volume changes occurring in postoperative below-knee residual limbs. J Rehabil Res Dev. 1988;25(2):11-18. [PMID:3361456]

8. Bolt A, de Boer-Wilzing VG, Geertzen JH, Emmelot $\mathrm{CH}$, Baars EC, Dijkstra PU. Variation in measurements of transtibial stump model volume: A comparison of five methods. Am J Phys Med Rehabil. 2010;89(5):376-84.

[PMID:20216057] http://dx.doi.org/10.1097/PHM.0b013e3181d3ea94

9. Zheng YP, Mak AF, Leung AK. State-of-the-art methods for geometric and biomechanical assessments of residual limbs: A review. J Rehabil Res Dev. 2001;38(5):487-504. [PMID:11732827]

10. Fernie GR, Holliday PJ, Lobb RJ. An instrument for monitoring stump oedema and shrinkage in amputees. Prosthet Orthot Int. 1978;2(2):69-72. [PMID:364403] http://dx.doi.org/10.3109/03093647809177770
11. Lilja M, Oberg T. Volumetric determinations with CAD/ CAM in prosthetics and orthotics: Errors of measurement. J Rehabil Res Dev. 1995;32(2):141-48. [PMID:7562654]

12. de Boer-Wilzing VG, Bolt A, Geertzen JH, Emmelot $\mathrm{CH}$, Baars EC, Dijkstra PU. Variation in results of volume measurements of stumps of lower-limb amputees: A comparison of 4 methods. Arch Phys Med Rehabil. 2011;92(6): 941-46. [PMID:21621671] http://dx.doi.org/10.1016/j.apmr.2011.01.007

13. Johansson S, Oberg T. Accuracy and precision of volumetric determinations using two commercial CAD systems for prosthetics: A technical note. J Rehabil Res Dev. 1998; 35(1):27-33. [PMID:9505250]

14. Douglas T, Solomonidis S, Sandham W, Spence W. Ultrasound imaging in lower limb prosthetics. IEEE Trans Neural Syst Rehabil Eng. 2002;10(1):11-21. [PMID:12173735] http://dx.doi.org/10.1109/TNSRE.2002.1021582

15. Sanders JE, Rogers EL, Abrahamson DC. Assessment of residual-limb volume change using bioimpedence. J Rehabil Res Dev. 2007;44(4):525-35. [PMID:18247249] http://dx.doi.org/10.1682/JRRD.2006.08.0096

16. Smith KE, Commean PK, Vannier MW. Residual-limb shape change: Three-dimensional CT scan measurement and depiction in vivo. Radiology. 1996;200(3):843-50. [PMID:8756942] http://dx.doi.org/10.1148/radiology.200.3.8756942

17. Commean PK, Brunsden BS, Smith KE, Vannier MW. Below-knee residual limb shape change measurement and visualization. Arch Phys Med Rehabil. 1998;79(7):772-82. [PMID:9685090] http://dx.doi.org/10.1016/S0003-9993(98)90355-0

18. Lilja M, Hoffmann P, Oberg T. Morphological changes during early trans-tibial prosthetic fitting. Prosthet Orthot Int. 1998;22(2):115-22. [PMID:9747995]

19. Lilja M, Oberg T. Proper time for definitive prosthetic fitting. J Prosthet Orthot. 1997;9(2):90-95. http://dx.doi.org/10.1097/00008526-199700920-00009

20. Labs KH, Tschoepl M, Gamba G, Aschwanden M, Jaeger KA. The reliability of leg circumference assessment: A comparison of spring tape measurements and optoelectronic volumetry. Vasc Med. 2000;5(2):69-74. [PMID:10943582] http://dx.doi.org/10.1177/1358836X0000500202

21. te Slaa A, Mulder P, Dolmans D, Castenmiller P, Ho G, van der Laan L. Reliability and reproducibility of a clinical application of a simple technique for repeated circumferential leg measurements. Phlebology. 2011;26(1):14-19. [PMID:20881309] http://dx.doi.org/10.1258/phleb.2009.009073

22. Lilja M, Johansson S, Oberg T. Relaxed versus activated stump muscles during casting for trans-tibial prostheses. Prosthet Orthot Int. 1999;23(1):13-20. [PMID:10355639] 
23. Sanders JE, Fatone S. Residual limb volume change: Systematic review of measurement and management. J Rehabil Res Dev. 2011;48(8):949-86. [PMID:22068373] http://dx.doi.org/10.1682/JRRD.2010.09.0189

24. Fernie GR, Holliday PJ. Volume fluctuations in the residual limbs of lower limb amputees. Arch Phys Med Rehabil. 1982;63(4):162-65. [PMID:7082139]

25. Sanders JE, Harrison DS, Cagle JC, Myers TR, Ciol MA, Allyn KJ. Post-doffing residual limb fluid volume change in people with trans-tibial amputation. Prosthet Orthot Int. 2012;36(4):443-49. [PMID:22588848] http://dx.doi.org/10.1177/0309364612444752

26. Fortington LV, Rommers GM, Postema K, van Netten JJ, Geertzen JH, Dijkstra PU. Lower limb amputation in Northern Netherlands: Unchanged incidence from 1991-1992 to 2003-2004. Prosthet Orthot Int. 2013;37(4):305-10.
[PMID:23327835]

http://dx.doi.org/10.1177/0309364612469385

Submitted for publication December 16, 2013. Accepted in revised form May 6, 2014.

This article and any supplementary material should be cited as follows:

Tantua AT, Geertzen JH, van den Dungen JJ, Breek JC, Dijkstra PU. Reduction of residual limb volume in people with transtibial amputation. J Rehabil Res Dev. 2014; 51(7):1119-26.

http://dx.doi.org/10.1682/JRRD.2013.11.0243

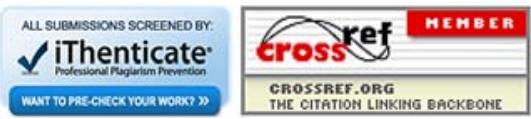

